\title{
Does the duration of smoking cessation have an impact on hospital admission and health-related quality of life amongst COPD patients?
}

This article was published in the following Dove Press journal:

International Journal of COPD

14 May 2014

Number of times this article has been viewed

\author{
Hazlinda Abu Hassan ${ }^{1,3}$ \\ Noorizan Abd Aziz $2, *$ \\ Yahaya Hassan ${ }^{2, *}$ \\ Fahmi Hassan ${ }^{2, *}$
}

'Malacca Pharmaceutical Services Division, Ministry of Health Malaysia, Ayer Keroh, Malaysia; ${ }^{2}$ Faculty of Pharmacy, Universiti Teknologi MARA, Puncak Alam, Malaysia; ${ }^{3}$ Department of Respiratory Medicine, Malacca Hospital, Jalan Mufti Haji Khalil, Malaysia

*These authors contributed equally to this work
Correspondence: Hazlinda Abu Hassan Malacca Pharmaceutical Services Division, Ministry of Health Malaysia, Ayer Keroh, Malacca 75450, Malaysia Email ganjil277@yahoo.com
Background: Lack of awareness among ex-smokers on the benefits of sustaining smoking cessation may be the main cause of their smoking relapse. This study explored health-related quality of life (HRQoL) and hospital admission amongst chronic obstructive pulmonary disease (COPD) patients according to the duration of smoking cessation.

Materials and methods: This study recruited COPD patients from a chest clinic who agreed to participate in a medication therapy-adherence program from January to June 2013. They were interviewed during their visits to obtain information regarding their smoking history and HRQoL. They were divided into three groups according to smoking status (sustained quitters, quit $\geq 5$ years; quitters, quit $<5$ years; and smokers, smoking at least one cigarette/day). The effects of the duration of cessation on HRQoL and hospital admission were analyzed using a multinomial logistic model.

Results: A total of 117 participants with moderate COPD met the inclusion criteria, who were comprised of 41 sustained quitters, 40 quitters, and 36 smokers. Several features were similar across the groups. Most of them were married elderly men (aged $>64$ years) with low-to-middle level of education, who smoked more than 33 cigarettes per day and had high levels of adherence to the medication regimen. The results showed that sustained quitters were less likely to have respiratory symptoms (cough, phlegm and dyspnea) than smokers (odds ratio 0.02, confidence interval $0-0.12 ; P<0.001)$. The hospital admission rate per year was increased in quitters compared to smokers (odds ratio 4.5, confidence interval 1.91-10.59; $P<0.005$ ).

Conclusion: A longer duration of quitting smoking will increase the benefits to COPD patients, even if they experience increased episodic respiratory symptoms in the early period of the cessation. Thus, the findings of this study show the benefits of early smoking cessation.

Keywords: HRQoL, hospital admission and hospital stay, chronic obstructive pulmonary disease (COPD)

\section{Introduction}

Chronic obstructive pulmonary disease (COPD) is a condition characterized by airflow limitation that is not fully recoverable because there is a progressive inflammatory response to the gases. ${ }^{1}$ Most epidemiological studies have reported smoking as the leading cause of COPD, and the disease causes much suffering and death worldwide. ${ }^{2-4}$ In Malaysia, the prevalence of COPD is moderate to severe, with approximately 448,000 cases in the country, ${ }^{5}$ and costs for COPD expenditures in 2010 were estimated at RM2.8 billion, while the number of cases is consistently increasing year by year. ${ }^{6}$

Studies have shown that since the 1960s, smoking is a major risk factor that has caused COPD, ${ }^{7}$ and about $50 \%$ of the smokers would have developed the disease. ${ }^{8}$ Many Malaysians know that smoking can be harmful to human lung function, but the 
number of smokers has been increasing due to the lack of awareness on the dangers of COPD. In a small study conducted among university students in Malaysia, it was found that smoking prevalence was $29 \%,{ }^{9}$ while an International Tobacco Control Malaysia report in 2012 reported that the occurrence of smoking had increased dramatically, especially among men, which accounted for almost half of all male smokers (46.4\%), and slightly (1.6\%) for women. ${ }^{10}$ In a study conducted by Lee et al, they found out that in Malacca, the rate of dropouts from smoking-cessation treatment programs was high, ${ }^{11}$ and this may indirectly affect the smokers, particularly those who have been suffering from COPD.

There is some evidence that smoking cessation in COPD sufferers lowers hospital-admission rates ${ }^{12,13}$ and improves health-related quality of life (HRQoL). ${ }^{14,15}$ Reduction in lung function may increase hospital admissions due to respiratory dyspnea, ${ }^{16}$ which may impact on health status. ${ }^{17}$ Improvement in mental health after a number of years since quitting may affect the HRQoL. ${ }^{18}$ However, there is little evidence of an association between smoking status and health outcomes, such as hospital admissions and HRQoL. As we know, there are factors that cause smokers to continue smoking. ${ }^{19}$ Furthermore, the lack of knowledge by ex-smokers about the benefits of long-term smoking cessation may be the main cause of their smoking relapse.

In order to establish evidence on the benefits of cessation, we carried out a study that aimed to determine the impact of the duration of smoking cessation on clinical outcomes, such as HRQoL and hospital admission, in COPD clinical care. Our hypothesis was that the duration of quitting smoking may be beneficial to COPD patients. There are very few published studies that have revealed the benefits of quitting smoking among COPD patients.

\section{Materials and methods}

A total of 198 subjects were recruited from the Chest Clinic of Malacca Hospital from January to June 2013. They agreed to volunteer in the Respiratory Medication Therapy Adherence Programme since 2011. This study was approved by the Medical Research Ethics Committee, Ministry of Health, Malaysia.

\section{Inclusion and exclusion criteria}

We recruited both smokers and ex-smokers based on the diagnosis of COPD made by physicians, as stated in the patients' clinical record with a Global initiative for chronic Obstructive Lung Disease (GOLD) criteria of a ratio of forced expiratory volume in 1 second $\left(\mathrm{FEV}_{1}\right)$ to forced vital capacity $(\mathrm{FVC})<0.7 .{ }^{1}$ Patients with main diagnoses of bronchiectasis, asthma, immobility, uncontrolled psychiatric illness, congestive cardiac failure, long-term oxygen-therapy use $\geq 15$ hours/day, active tuberculosis, diffuse interstitial lung diseases, or pulmonary thromboembolic disease were excluded from the study. Patients who were admitted due to exacerbation 4 weeks before measuring the HRQoL during the follow-up visit were excluded as well.

\section{Patient data}

In order to obtain the patients' data, a medical record review was carried out, which extracted data on demographics, comorbidities, previous admissions, medication regimens, and smoking-cessation history. A semistructured face-to-face interview was conducted to get information on the HRQoL (self-reported), smoking history, patients' adherence to medication by using a modified Morisky Medication Adherence Score (high adherence if score $>8$, medium adherence if score $6-<8$, and low adherence if score $<6$ ), ${ }^{20}$ and inhaler-technique asessment. ${ }^{21,22}$ The data were collected by an independent data collector who was not involved in the routine care.

\section{Smoking-cessation status}

Smoking status among the patients was derived based upon self-report taken from each visit, and monitored with the Fagerström Test for Nicotine Dependence (Malay version), ${ }^{23}$ which was updated for each visit. The selection of cessation duration was based on studies that showed clinical effects that are observed after 5 years of long-term quitting. . $24^{24}$ Smoking status among the patients was classified as exsmokers (sustained quitters and quitters) and smokers. A sustained quitter was defined as someone who had given up smoking more than 5 years prior to the interview, which met our definition of successful smoking cessation. Those respondents who had given up smoking less than 5 years previously were considered quitters. A smoker was defined as someone who had smoked at least one cigarette per day on a regular basis for at least 1 year.

\section{HRQoL measurement}

HRQoL was measured using the Clinical COPD Questionnaire (CCQ), which is a short questionnaire with great evaluative properties in measuring HRQoL. ${ }^{25,26}$ The CCQ was chosen for this study because it has proven reliability, validity, responsiveness, and high reproducibility. ${ }^{25}$ In addition, the CCQ is very concise and easily understood by patients, ${ }^{27}$ while providing information on symptoms and damage that better 
reflected their HRQoL. ${ }^{28}$ Permission was obtained prior to this study. The CCQ was administered for all subjects during each visit, with a different order for each patient. High total CCQ scores indicated poor HRQoL. The weekly version was used for the purpose of this study, and Cronbach's alpha $(\alpha=0.83)$ indicated that there was homogeneity among the individual items in the questionnaires. The CCQ contains ten items, which are divided into three domains: symptoms, functional state, and mental state. The CCQ had been chosen as the best method for use in daily practice, as it is easy to administer, possesses good patient preference, and has similarity with psychometric properties. ${ }^{27}$

\section{Statistical analysis}

All the data were double-entered into SPSS version 18.0 (IBM, Armonk, NY, USA). The patients' demographic information and medical profile were calculated in the forms of means and standard deviation for continuous variables and percentages for categorical variables. Values of $P<0.05$ were considered statistically significant. Simple logistic regression comparison between participants was analyzed using one-way analysis of variance for numerical variables and Pearson's $\chi^{2}$ or Fisher's exact test for categorical variables. To better describe the dependent variables or outcomes associated within the groups of participants, multinomial logistic analysis was used to obtain odds ratios. We compared sustained quitters with smokers, and quitters with smokers.

\section{Results}

\section{Characteristics of study participants}

During the study period, 117 patients met the inclusion criteria. There were 41 sustained quitters, 40 quitters, and 36 smokers. Table 1 displays patients' characteristics. The patients were mostly married men, over 64 years old, not highly educated, and suffering from moderate-to-severe $\mathrm{COPD}$, as reflected by mean $\mathrm{FEV}_{1} \sim 50 \%$ of the predicted value. The participants had begun smoking when they were 15 years old, and smoked more than 32 cigarettes per day. The participants reported a mean of 1.00 serious quit attempts and $82.9 \%$ of them quit with nonpharmacological treatment. About $50 \%$ of the subjects reported having comorbidities, which included hypertension, dyslipidemia, diabetes, osteoporosis, obesity, and hormonal disorder. The use of pulmonary medications was similar among the groups.

Table 2 shows a summary of the clinical characteristics and HRQoL variables of the three categories of patients. Mean annual hospital admission was statistically significant or was found to be different among quitters compared to smokers (odds ratio 4.5, confidence interval 1.91-10.59; $P=0.005$ ), while mean length of stay was not significantly different between groups.

Differences in domain scores of the CCQ were not statistically significant, except for the symptom domain, which showed improvement in sustained quitters compared to smokers (odds ratio 0.02, confidence interval $0-0.12$; $P=0.001)$. In short, patients who were sustained quitters were less likely to have high symptoms than smokers if the scale of symptoms was decreased.

\section{Discussion}

There are several limitations of this study. Data were compared with respect to demographics, comorbidities, smoking status, hospital admission, medication adherence and health status, from the main hospital in Malacca. Smoking is a personal health problem, and the patients received routine monitoring in the Chest Department, which is also the only such department in the state. Some patients felt that quitting smoking is a horrible experience ${ }^{19}$ and improved medication use could lead to better health even in those who fail to stop smoking. This study set out with the aim of assessing the effects of smoking cessation on hospital admission and HRQoL. The results showed that quitters were more often readmitted than smokers without change in HRQoL compared to smokers. Another finding upon hospital admission was that sustained quitters had improved symptoms, such as cough, shortness of breath, and phlegm production, compared to smokers. Very little was found in the literature on the effects of smoking cessation on HRQoL in COPD, except for intervention studies. The positive impact of smoking cessation on mortality and morbidity is well established, ${ }^{13}$ but few studies have showed the relevant impact on HRQoL and readmission. Furthermore, HRQoL had been determined in several intervention studies to achieving management goals in COPD. ${ }^{29,30}$

Unlike the others studies examining HRQoL and smoking status, comorbid conditions were considered as potential confounders influencing changes in HRQoL and were controlled in the analysis. The participants were selected homogeneously, based on demographics, COPD severity, respiratory treatment, and medication adherence and comorbidity. Interviewed participants $(n=117,95.7 \%$ male and moderate COPD) were representative of the total group with a mean age 65.5 years, while $52.14 \%$ had at least one additional comorbid chronic condition. Assuming that the prediction of quit smoking may be beneficial to patients with COPD, there are two possibilities of benefits of cessation. Firstly, quit smoking can reduce hospital admissions and 
Table I Characteristics of the study population during study period $(n=I \mid 7)$

\begin{tabular}{|c|c|c|c|c|}
\hline & Sustained quitters $(n=4 I)$ & Quitters $(n=40)$ & Smokers $(n=36)$ & $P$-value ${ }^{a}$ \\
\hline Age, years, mean (SD) & $67.46(8.63)$ & $64.70(6.77)$ & $64.08(8.86)$ & 0.15 \\
\hline \multicolumn{5}{|l|}{ Sex, $n(\%)$} \\
\hline Male & $40(97.6)$ & $39(97.5)$ & 33 (9।.7) & \multirow[t]{2}{*}{0.35} \\
\hline Female & I (2.4) & I (2.5) & $3(8.3)$ & \\
\hline \multicolumn{5}{|l|}{ Ethnicity, n (\%) } \\
\hline Malay & $23(56.1)$ & $23(57.5)$ & $20(55.6)$ & \multirow[t]{4}{*}{0.43} \\
\hline Chinese & 17 (4I.5) & $14(35.0)$ & $12(33.3)$ & \\
\hline Indian & 0 & $2(5.0)$ & $4(I I . I)$ & \\
\hline Other & I (2.4) & $\mathrm{I}(2.5)$ & $0(0)$ & \\
\hline \multicolumn{5}{|l|}{ Marital status, n (\%) } \\
\hline Single & $2(4.9)$ & 0 & I (2.8) & \multirow[t]{2}{*}{0.38} \\
\hline Married & $39(95.1)$ & $40(100.0)$ & $35(97.2)$ & \\
\hline \multicolumn{5}{|l|}{ Education level, n (\%) } \\
\hline Uneducated & $4(9.8)$ & I (2.5) & $4(I I . I)$ & \multirow[t]{4}{*}{0.35} \\
\hline Elementary school & $24(58.5)$ & $26(65.0)$ & $22(6 \mathrm{I} . \mathrm{I})$ & \\
\hline Middle school & II (26.8) & $13(32.5)$ & $7(19.4)$ & \\
\hline High school/college & $2(4.9)$ & 0 & $3(8.3)$ & \\
\hline \multicolumn{5}{|l|}{ Occupation, n (\%) } \\
\hline Government & $0(2.4)$ & $2(5.0)$ & $3(8.3)$ & \multirow[t]{4}{*}{0.56} \\
\hline Private & $4(9.8)$ & $2(5.0)$ & $4(11.1)$ & \\
\hline Business & I (2.4) & I (2.5) & $3(8.3)$ & \\
\hline Retired & $35(85.4)$ & $35(87.5)$ & $26(72.2)$ & \\
\hline $\mathrm{FEV}, \%$, mean $(\mathrm{SD})$ & $58.3(11.2)$ & $57.5(10.5)$ & $55.2(9.3)$ & 0.21 \\
\hline Age began smoking in years, mean (SD) & $16.05(3.38)$ & $16.75(3.74)$ & $15.47(5.96)$ & 0.64 \\
\hline Cigarettes per day, mean (SD) & 32.11 (12.83) & $35.88(9.86)$ & $33.47(14.87)$ & 0.38 \\
\hline No attempt at quitting after getting COPD, mean (SD) & $1.03(1.31)$ & $0.98(1.32)$ & $1.14(1.31)$ & 0.54 \\
\hline Experience on cessation treatment, $n(\%)$ & $5(21.37)$ & $7(20.99)$ & $8(22.22)$ & 0.24 \\
\hline SABA, n (\%) & $41(100.0)$ & $40(100.0)$ & $35(97.2)$ & 0.32 \\
\hline SAAC, n (\%) & $29(70.7)$ & $24(60.0)$ & $24(66.7)$ & 0.59 \\
\hline LAAC, n (\%) & $18(43.9)$ & $18(45.0)$ & $15(4 \mid .7)$ & 0.96 \\
\hline ICS, n (\%) & $26(63.4)$ & $28(70.0)$ & $22(61.11)$ & 0.12 \\
\hline Methylxanthines, n (\%) & $26(63.4)$ & $28(70.0)$ & $16(44.4)$ & 0.064 \\
\hline Annual RMTAP attendance (mean, SD) & $2.93(1.85)$ & $1.98(1.21)$ & $2.11(1.77)$ & 0.021 \\
\hline Number of medications, mean (SD) & $6.39(2.84)$ & $6.50(2.09)$ & $4.75(2.23)$ & 0.003 \\
\hline Morisky score, mean (SD) & $7.83(0.28)$ & $7.86(0.24)$ & $7.78(0.83)$ & 0.83 \\
\hline \multicolumn{5}{|l|}{ Inhaler technique, $\mathrm{n}(\%)$} \\
\hline Proper & $37(90.24)$ & $33(100.0)$ & $35(97.22)$ & \multirow[t]{2}{*}{0.42} \\
\hline Improper & $4(9.76)$ & $7(17.5)$ & I (2.78) & \\
\hline Body mass index kg/m², mean (SD) & $23.63(4.33)$ & $23.62(3.19)$ & $22.04(4.32)$ & 0.14 \\
\hline Comorbidity, n (\%) & $23(56.10)$ & $21(52.5)$ & $17(47.22)$ & 0.67 \\
\hline Number of comorbid conditions, mean (SD) & $1.88(1.18)$ & $1.65(1.25)$ & $1.22(1.17)$ & 0.067 \\
\hline Hypertension, n (\%) & $21(51.22)$ & $17(42.50)$ & $16(44.44)$ & 0.38 \\
\hline Dyslipidemia, n (\%) & $12(29.3)$ & $6(15.0)$ & $7(19.4)$ & 0.28 \\
\hline Diabetes mellitus, n (\%) & $8(19.5)$ & $13(32.5)$ & $4(11.1)$ & 0.07 \\
\hline Obesity, n (\%) & 0 & 0 & $\mathrm{I}(2.8)$ & 0.32 \\
\hline Depression, n (\%) & I (2.4) & 0 & 0 & 0.39 \\
\hline Osteoporosis, n (\%) & 0 & 0 & $2(5.6)$ & 0.10 \\
\hline Hormonal disorder, n (\%) & $2(4.9)$ & 0 & $\mathrm{I}(2.8)$ & 0.38 \\
\hline
\end{tabular}

Notes: aPearson's chi-squared/Fisher's exact test were applied in calculating $P$-values.

Abbreviations: SD, standard deviation; COPD, chronic obstructive pulmonary disease; FEV ${ }_{1}$, forced expiratory volume in I second; SABA, short-acting $\beta_{2}$-agonist; LABA, long-acting $\beta_{2}$-agonist; SAAC, short-acting anticholinergic; LAAC, long-acting anticholinergic; ICS, inhaled corticosteroid; RMTAP, Respiratory Medication Therapy Adherence Programme.

reduce respiratory symptoms (dyspnoea, phlegm, and cough), compared to smokers. Secondly, due to the long period of cessation, prompted sustained quitters also obtain similar benefits, but quitters showed significantly high hospital admission compared to sustained quitters. This finding supports the theory that smoking cessation increases respiratory symptoms but may be beneficial to the lungs in slowing the rapid decline of lung function. ${ }^{31}$ The effect of long-term smoking cessation had also been reported by Lapperre et al, who suggested that the increase in respiratory symptoms may be caused by changes in the bronchial epithelium, which is considered as the process of recovery for smokers after 3.5 
Table 2 Summary of clinical outcomes

\begin{tabular}{|c|c|c|c|c|c|c|c|c|}
\hline & $\begin{array}{l}\text { Sustained } \\
\text { quitters (SQ) } \\
(n=4 I)\end{array}$ & $\begin{array}{l}\text { Quitters (Q) } \\
(n=40)\end{array}$ & $\begin{array}{l}\text { Smokers (S) } \\
(n=36)\end{array}$ & $P$-value & $\begin{array}{l}\text { SQ vs S } \\
\text { Odds ratio } \\
(95 \% \mathrm{Cl})\end{array}$ & $P$-value & $\begin{array}{l}\text { Q vs S } \\
\text { Odds ratio } \\
(95 \% \mathrm{Cl})\end{array}$ & $P$-value \\
\hline $\begin{array}{l}\text { Annual hospital } \\
\text { admission due to } \\
\text { COPD, mean (SD) }\end{array}$ & $0.44(0.74)$ & $1.43(1.17)$ & $0.97(1.46)$ & 0.05 & $1.43(0.57-3.62)$ & 0.05 & $4.50(1.91-10.59)$ & $<0.05$ \\
\hline $\begin{array}{l}\text { Number of days } \\
\text { warded, mean (SD) }\end{array}$ & $2.1(3.65)$ & $8.43(9.78)$ & $5.39(8.62)$ & 0.14 & $1.02(0.77-1.13)$ & 0.188 & $1.04(0.98-1.11)$ & 0.19 \\
\hline CCQ symptoms & $1.94(0.43)$ & $2.39(0.61)$ & $2.60(0.80)$ & $<0.00 \mathrm{I}^{\mathrm{a}}$ & $0.02(0-0.12)$ & $<0.001$ & $0.61(1.12-3.02)$ & 0.54 \\
\hline CCQ functional & $2.20(0.49)$ & $2.43(0.78)$ & $2.61(0.72)$ & $0.03^{b}$ & $2.06(0.65-6.52)$ & 0.22 & $0.75(0.24-2.37)$ & 0.63 \\
\hline CCQ mental & $1.70(0.84)$ & $1.58(0.96)$ & $1.92(1.14)$ & 0.31 & $2.44(0.42-14.22)$ & 0.32 & $0.76(0.14-4.24)$ & 0.76 \\
\hline
\end{tabular}

Notes: Post hoc analyses with Tukey's honest significant difference - a"smokers and sustained quitters" and "quitters and sustained quitters"; b"smokers and sustained quitters".

Abbreviations: $\mathrm{Cl}$, confidence interval; SD standard deviation; COPD, chronic obstructive pulmonary disease; CCQ, Clinical COPD Questionnaire.

years of quitting smoking. ${ }^{24}$ The other factor that may have led to frequent hospital admittance was the length of time patients had suffered from COPD. A study carried out by Cao et al found that patients with a longer history of diagnosis had approximately twofold-higher chances of frequent hospital admissions than patients with shorter duration who had been diagnosed with COPD (odds ratio 2.51, 95\% confidence interval 1.39-4.53). ${ }^{32}$

Although COPD patients successfully quit smoking, their respiratory functions decrease with increased age. ${ }^{33}$ Moreover, patients with COPD have a low perception of dyspnea. ${ }^{17} \mathrm{In}$ this study, comparing sustained quitters with quitters showed that the mean score for CCQ symptoms of sustained quitters was significantly improved compared to smokers. Therefore, this finding reflected that sustained quitters generally have more dyspnea symptoms than smokers. Therefore, the decline of lung function and having poor symptoms do not reflect poor HRQoL. Jones et al also reported that decline in the lung-function parameter was not strongly associated with perception or response on symptoms and HRQoL. ${ }^{34}$

Smoking cessation has been related to HRQoL improvement. Previous studies have supported the view that smoking cessation can improve HRQoL. ${ }^{14,15}$ In contrast to earlier findings, however, the findings of the previous study showed that quitting smoking after smoking for long durations did not improve HRQoL. ${ }^{14}$ Further investigations focusing on the HRQoL impact of quitting smoking are needed, with a large prospective study in Malaysia to find firm evidence of the benefits of long-term cessation specifically HRQoL by using the sensitive tool. As far as the data are concerned, this study managed to provide support for differences in HRQoL in the short term for quitting among COPD patients. ${ }^{15,35}$

Most COPD patients quit smoking with nonpharmacological treatment and stop after the occurrence of health problems, as health concerns are a major reason to quit smoking. ${ }^{36}$
After a bad experience disappears, they feel that quitting smoking is not beneficial to them, which consequently makes it difficult for them to remove the habit. In this situation, focus should be given to pharmacological treatment. Ultimately, to overcome the limitations of the study design, these results need to be confirmed in prospective, long-term studies with large sample sizes. Despite its imperfections, this study contributes to an investigation that has been lacking so far, and may provide new insight into the process of smoking cessation among patients with COPD in Malaysia.

\section{Conclusion}

In summary, this study supports differences in HRQoL by smoking status. Sustained quitters had fewer symptoms than smokers, resulting in insignificant differences in hospital admissions, which contrasted with the quitters. In short, the longer the duration of quitting smoking may have health benefits for COPD patients, even if they have to accept discomfort in the early stage of smoking cessation. These findings challenge the assumption that quitting smoking alone after years of smoking will result in substantially improved HRQoL and reduced hospital admissions. The result may have implications for medication-management programs to encourage patients to stop smoking, as well as focus on patients' adherence to the treatment. Further research is required to corroborate and determine the longer-term implications or impact of quitting duration on clinical outcomes.

\section{Acknowledgments}

The authors would like to thank the patients and staff from the Chest Clinic of the Malacca Hospital. This study received funding from the National Institutes of Health (NIH), Ministry of Health Malaysia. We would also like to thank the Clinical Research Centre (CRC), Malacca Hospital, and the Ministry of Health Malaysia for supporting this study. 


\section{Disclosure}

The authors report no conflicts of interest in this work.

\section{References}

1. Pauwels RA, Buist AS, Calverley PM, Jenkins CR, Hurd SS. Global strategy for the diagnosis, management, and prevention of chronic obstructive pulmonary disease. NHLBI/WHO Global Initiative for Chronic Obstructive Lung Disease (GOLD) Workshop summary. Am J Respir Crit Care Med. 2001;163:1256-1276.

2. Viegi G, Scognamiglio A, Baldacci S, Pistelli F, Carrozzi L. Epidemiology of chronic obstructive pulmonary disease (COPD). Respiration. 2001;68:4-19.

3. Doll R, Peto R, Boreham J, Sutherland I. Mortality in relation to smoking: 50 years' observations on male British doctors. BMJ. 2004;328:1519.

4. Mannino D, Buist A. Global burden of COPD: risk factors, prevalence, and future trends. Lancet. 2007;370:765-773.

5. Regional COPD Working Group. COPD prevalence in 12 Asia-Pacific countries and regions: projections based on the COPD prevalence estimation model. Respirology. 2003;8:192-198.

6. The Star Online. Obstruction ahead! 2012. Available from: http://www. thestar.com.my/Lifestyle/Health/2012/05/06/Obstruction-ahead.aspx. Accessed December 11, 2013.

7. Forey BA, Thornton AJ, Lee PN. Systematic review with meta-analysis of the epidemiological evidence relating smoking to COPD, chronic bronchitis and emphysema. BMC Pulm Med. 2011;11:36.

8. Lundbäck B, Linberg A, Lindström $\mathrm{M}$, et al. Not 15 but $50 \%$ smokers develop COPD? Report from the Obstructive Lung Disease in Northern Sweden Studies. Respir Med. 2003;97:115-122.

9. Al-Naggar RA, Al-Dubai SA, Al-Naggar TH, Chen R, Al-Jashamy K. Prevalence and of smoking and associated factors among Malaysian University students. Asian Pac J Cancer Prev. 2011;12:619-624.

10. Malaysian Health Promotion Board. ITC Malaysia National Report 2012 (March): findings from Wave 1 to 4 surveys (2005-2009). Available from: http://www.mysihat.gov.my/v2/promosi/images/stories/ pusatmaklumat/itcreport. Accessed February 12, 2012.

11. Lee ML, Hassali MA, Shafie AA. A qualitative exploration of the reasons for the discontinuation of smoking cessation treatment among Quit Smoking Clinics' defaulters and health care providers in Malaysia. Res Soc Adm Pharm. 2013;9:405-418.

12. Godtfredsen NS, Vestbo J, Osler M, Prescott E. Risk of hospital admission for COPD following smoking cessation and reduction: a Danish population study. Thorax. 2002;57:967-972.

13. Godtfredsen NS, Lam TH, Hansel TT, et al. COPD-related morbidity and mortality after smoking cessation: status of the evidence. Eur Respir J. 2008;32:844-853

14. Sarna L, Bialous SA, Cooley ME, Jun HJ, Feskanich D. Impact of smoking and smoking cessation on health-related quality of life in women in the Nurses' Health Study. Qual Life Res. 2008;17:1217-1727.

15. Papadopoulos G, Vardavas CI, Limperi M, Linardis A, Georgoudis G, Behrakis P. Smoking cessation can improve quality of life among COPD patients: validation of the clinical COPD questionnaire into Greek. $B M C$ Pulm Med. 2011;11:13.

16. Makris D, Moschandreas J, Damianaki A, et al. Exacerbations and lung function decline in COPD: new insights in current and ex-smokers. Respir Med. 2007;101:1305-1312.

17. Seemungal TAR, Donaldson GC, Paul EA, et al. Effect of exacerbation on quality of life in patients with chronic obstructive pulmonary disease. Am J Respir Crit Care Med. 1998;157:1418-1422.

18. Mino Y, Shigemi J, Otsu T, Tsuda T, Babazono A. Does smoking cessation improve mental health? Psychiatry Clin Neurosci. 2000;54: 169-172.
19. Eklund BM, Nilsson S, Hedman L, Lindberg I. Why do smokers diagnosed with COPD not quit smoking? A qualitative study. Tob Induc Dis. 2012;10:17.

20. Morisky DE, Ang A, Krousel-Wood M, Ward HJ. Predictive validity of a medication adherence measure in an outpatient setting. $J$ Clin Hypertens (Greenwich). 2008;10:348-354.

21. Basheti IA, Armour CL, Reddel HK, Bosnic-Anticevich SZ. Long-term maintenance of pharmacists' inhaler technique demonstration skills. $\mathrm{Am}$ J Pharm Educ. 2009;73:32.

22. Al-Jahdali H, Ahmed A, Al-Harbi A, et al. Improper inhaler technique is associated with poor asthma control and frequent emergency department visits. Allergy Asthma Clin Immunol. 2013;9:8.

23. Yee HA, $\mathrm{Ng} \mathrm{C}$, Rusdi A. Validation of the Malay version of Fagerstrom Test for Nicotine Dependence (FTND-M) among a group of male staffs in a university hospital. Malays J Psychiatry. 2011;20(1):1-7.

24. Lapperre TS, Sont JK, van Schadewijk A, et al. Smoking cessation and bronchial epithelial remodelling in COPD: a cross-sectional study. Respir Res. 2007;8:85.

25. van der Molen T, Willemse BW, Schokker S, ten Hacken NH, Postma DS, Juniper EF. Development, validity and responsiveness of the Clinical COPD Questionnaire. Health Qual Life Outcomes. 2003;1:13.

26. Kocks JWH, Tuinenga MG, Uil SM, van den Berg JW, Ståhl E, van der Molen T. Health status measurement in COPD: the minimal clinically important difference of the clinical COPD questionnaire. Respir Res. 2006;7:62.

27. Tsiligianni IG, van der Molen T, Moraitaki D, et al. Assessing health status in COPD. A head-to-head comparison between the COPD assessment test (CAT) and the clinical COPD questionnaire (CCQ). BMC Pulm Med. 2012;12:20.

28. Daudey L, Peters JB, Molema J, et al. Health status in COPD cannot be measured by the St George's Respiratory Questionnaire alone: an evaluation of the underlying concepts of this questionnaire. Respir Res. 2010;11:98.

29. Monninkhof E, van der Valk P, van der Palen J, van Herwaarden C, Partridge M. Self-management education for patients with chronic obstructive pulmonary disease: a systematic review. Thorax. 2003;22: 394-398.

30. Niesink A, Trappenburg JC, de Weert-van Oene GH, Lammers JW, Verheij TJ, Schrijvers AJ. Systematic review of the effects of chronic disease management on quality-of-life in people with chronic obstructive pulmonary disease. Respir Med. 2007;101:2233-2239.

31. Willemse BW, Postma DS, Timens W, ten Hacken NH. The impact of smoking cessation on respiratory symptoms, lung function, airway hyperresponsiveness and inflammation. Eur Respir J. 2004;23: 464-476.

32. Cao Z, Ong KC, Eng P, Tan WC, Ng TP. Frequent hospital readmissions for acute exacerbation of COPD and their associated factors. Respirology. 2006;11:188-195.

33. Connolly MJ, Lowe D, Anstey K, Hosker HS, Pearson MG, Roberts CM. Admissions to hospital with exacerbations of chronic obstructive pulmonary disease: effect of age related factors and service organisation. Thorax. 2006;61:843-848.

34. Jones P, Anderson J, Calverley P, et al. Health status in the TORCH study of COPD: treatment efficacy and other determinants of change. Respir Med. 2011;12:71.

35. Kotz D, Wesseling G, Aveyard P, van Schayck OC. Smoking cessation and development of respiratory health in smokers screened with normal spirometry. Respir Med. 2011;105:243-249.

36. McCaul KD, Hockemeyer JR, Johnson RJ, Zetocha K, Quinlan K, Glasgow RE. Motivation to quit using cigarettes: a review. Addict Behav. 2006;32:42-56. 
International Journal of COPD

\section{Publish your work in this journal}

The International Journal of COPD is an international, peer-reviewed journal of therapeutics and pharmacology focusing on concise rapid reporting of clinical studies and reviews in COPD. Special focus is given to the pathophysiological processes underlying the disease, intervention programs, patient focused education, and self management protocols.

This journal is indexed on PubMed Central, MedLine and CAS. The manuscript management system is completely online and includes a very quick and fair peer-review system, which is all easy to use. Visit $\mathrm{http}: / /$ www.dovepress.com/testimonials.php to read real quotes from published authors.

Submit your manuscript here: http://www.dovepress.com/international-journal-of-copd-journa 